\title{
Sexual dysfunction in men with rheumatic diseases
}

\author{
Laura Groseanu ${ }^{1,2}$, Vlad Condrache ${ }^{1}$, Andra Balanescu ${ }^{1,2}$, Violeta Bojinca ${ }^{1,2}$, \\ Daniela Opris Belinski, ${ }^{1,2}$, Sanziana Daia-Iliescu ${ }^{1,2}$, Claudia Cobilinschi ${ }^{1,2}$, \\ Diana Mazilu ${ }^{1,2}$, Ruxandra Ionescu ${ }^{1,2}$ \\ 1 "Carol Davila" University of Medicine and Pharmacy, Bucharest, Romania \\ 2 "Sf. Maria" Clinical Hospital, Bucharest, Romania
}

\begin{abstract}
Objective. To evaluate sexual function in a cohort of men with rheumatic disease compared to healthy controls. Patients and methods. The study included 60 patients (ankylosing spondylitis, rheumatoid arthritis, systemic sclerosis, gout, psoriatic arthritis) and 60 healthy age-matched controls. Sexual function of patients and controls was evaluated by the Sexual Health Inventory for Men and a detailed questionnaire.

Results. The mean age of study group was 45,26 (7.8) years. In $90 \%$ of the cases sexual life changed after diagnosis: only $1.67 \%$ described their sexual life as being very satisfying, while $21.67 \%$ as being satisfying, $68.33 \%$ as not satisfying and $8.33 \%$ as absent. $40 \%$ of the patients had diminished libido, significantly lower compared to the study group $(p=0.043)$. Most patients presented with mild erectile dysfunction $(60 \%)$, while most of the systemic sclerosis patients presented with mild to moderate erectile dysfunction. Erectile dysfunction scores were significantly lower compared to controls (0.009).

$55 \%$ of the patients reported no influence of the treatment on their sexual life, $38 \%$ of the patients reported that specific treatment improved their sexual life. There was no statistical difference between SHIM scores of patients using biological therapies and other drugs.

Conclusions. This work suggests that men with rheumatic conditions have a worse sexual function in comparison with healthy control. However, specific disease parameters or treatments were not linked to sexual dysfunction.
\end{abstract}

Keywords: rheumatic disease, men sexual dysfunction

\section{INTRODUCTION}

Sexual dysfunction (SD) is a widespread worldwide health problem especially in middle-aged and elderly people (1). Based on epidemiological data from different geographical regions, the prevalence of SD ranged from $18.4 \%$ to $34.2 \%$ among men (2). Male SD mainly includes diminished libido, abnormal ejaculation and erectile dysfunction (ED) (3).

Rheumatic diseases may affect all aspects of life including sexual functioning. Sexual health and family planning are important considerations not only for patients but also for the health practitioners who treat them, yet these issues are rarely comprehensively addressed in clinical practice (1). The reasons for disturbing sexual functioning are multifactorial and comprise disease-related factors as well as therapy. These factors include: pain, fatigue, stiffness, functional impairment, depression, anxiety, negative body image, reduced libido, hormonal imbalance, and drug treatment (3). Physical problems, emotional problems and partnership difficulties arising from disease-related stress contribute to a less active and often less enjoyable sex life. Chronic pain, fatigue and low self-esteem can reduce an individual's sexual interest. Furthermore, specific sexual dysfunction can be caused by several rheumatic diseases, and are related to the nature of prevailing symptoms. Sexual problems created by both the physical changes of the illness and its attendant emotional distresses not only affect people with rheumatic diseases, but also their partners (1).

To evaluate the effects of rheumatic disease on sexual function of men, we conducted a questionnaire based study on a cohort of patients with five rheumatic diseases and compare them with a control group. The association between sexual dysfunction 
and specific parameters of disease activity and treatments were also well thought-out.

\section{MATHERIAL AND METHODS}

We performed a cohort study on 60 male patients hospitalized in „Sfanta Maria“ Clinical Hospital between august 2019 and march 2020. Inclusion criteria were: age between 18 and 60 years, signed inform consent, diagnosed with one out of the five rheumatic conditions: rheumatoid arthritis (RA), ankylosing spondylitis (AS), gout, systemic sclerosis (SS) and psoriatic arthritis (PsA).

Each patient anonymous completed a questionnaire including personal data (age, educational status, marital status, residence), history of the rheumatic condition (diagnosis, date of diagnosis, treatment, disease activity status as assessed by the attending physician), associated medical conditions, changes of physical appearance, psychological status, social relationships after diagnosis, sexual life (general evaluation before diagnosis, global changes after diagnosis, how the disease impairs sexual life, sexual dysfunction after diagnosis - erectile dysfunction, diminished libido, premature ejaculation, lack of ejaculation-, influence of drugs on sexual life). All patients also fulfilled the Sexual Health Inventory for Men (SHIM) questionnaire (Figure 1).

Based on SHIM, patients were classified as having mild erectile dysfunction $-17-22$ points, mild to moderate erectile dysfunction, 12-16 moderate erectile dysfunction $-8-11$ points, severe erectile dysfunction $-5-7$ points.

An aged matched control group of 60 patients completed the same questionnaires.

\section{RESULTS}

\section{Characteristics of study group}

The study group included 22 (36.66\%) patients with AS, 10 (16.66\%) with RA, 9 (15\%) with SS, 11 $(18.33 \%)$ with PsA and 8 (13.33\%) with gout. The medium age of study group was 45.26 (7.8) years. $60 \%$ of the patients came from urban residence and $80 \%$ had a high educational level. $64.81 \%$ of those patients had associated medical conditions. Mean disease duration was 8.18 (2.13) years for AS patients, 13.3 (4.1) for RA patients, 5.11 (1.8) years for SS patients, 8.63 (2.9) for PsA patients and 4.5 (1.3) years for gout patients.

$54.54 \%$ of AS patients, $50 \%$ of RA, $66.66 \%$ of SS, $45,45 \%$ of PsA had active disease based on specific evaluation of attending physician [based on specific cut-offs of ASDAS for AS (4), DAS28-CRP for RA (5), EScSG disease activity indices for SSc (6), DAPSA for PsA (7)]. All gout patients were admitted in the clinic for disease flares.

$66.66 \%$ of the patients had children before diagnosis, only one patient with ankylosing spondylitis had conceived after diagnosis.

\section{Over the past 6 months}

1.How do you rate your confidence that you could get and keep an erection?

$\begin{array}{ccccc}\text { Very low } & \text { Low } & \text { Moderate } & \text { High } & \text { Very high } \\ 1 & 2 & 3 & 4 & 5\end{array}$

2. When you had erections with sexual stimulation, how often were your erections hard enough for penetration (entering your partner)?

$\begin{array}{ccccc}\text { No sexual activity } & \begin{array}{c}\text { Almost never } \\ \text { or never }\end{array} & \begin{array}{c}\text { A few times } \\ \text { (much less than } \\ \text { half the time }\end{array} & \begin{array}{c}\text { Sometimes } \\ \text { (about half } \\ \text { the time }\end{array} & \begin{array}{c}\text { Most times } \\ \text { (much more than } \\ \text { half the time } \\ \text { or always }\end{array} \\ 0 & 1 & 2 & 3 & 4\end{array}$

3. During sexual intercourse, how often were you able to maintain your erection after you had penetrated (entered) your partner?

$\begin{array}{ccccc}\begin{array}{c}\text { Did not attempt } \\ \text { intercourse }\end{array} & \begin{array}{c}\text { Almost never } \\ \text { or never }\end{array} & \begin{array}{c}\text { A few times } \\ \text { (much less than } \\ \text { half the time }\end{array} & \begin{array}{c}\text { Sometimes } \\ \text { (about half } \\ \text { the time }\end{array} & \begin{array}{c}\text { Almost always } \\ \text { or always }\end{array} \\ 0 & 1 & 2 & 3 & 5\end{array}$

4. During sexual intercourse, how difficult was to maintain your erection to completion of intercourse?

\begin{tabular}{|c|c|c|c|c|c|}
\hline $\begin{array}{l}\text { Did not attempt } \\
\text { intercourse }\end{array}$ & Extremely difficult & Very difficult & Difficult & Slightly difficult & Not difficult \\
\hline 0 & 1 & 2 & 3 & 4 & 5 \\
\hline \multicolumn{6}{|c|}{ When you attempted sexual intercourse, how often was it satisfactory for you? } \\
\hline $\begin{array}{l}\text { Did not attempt } \\
\text { intercourse }\end{array}$ & $\begin{array}{c}\text { Almost never } \\
\text { or never }\end{array}$ & $\begin{array}{l}\text { A few times } \\
\text { (much less than } \\
\text { half the time }\end{array}$ & $\begin{array}{l}\text { Sometimes } \\
\text { (about half } \\
\text { the time }\end{array}$ & $\begin{array}{l}\text { Most times } \\
\text { (much more than } \\
\text { half the time }\end{array}$ & $\begin{array}{l}\text { Almost always } \\
\text { or always }\end{array}$ \\
\hline 0 & 1 & 2 & 3 & 4 & 5 \\
\hline
\end{tabular}

FIGURE 1. Sexual Health Inventory for Men questionnaire 


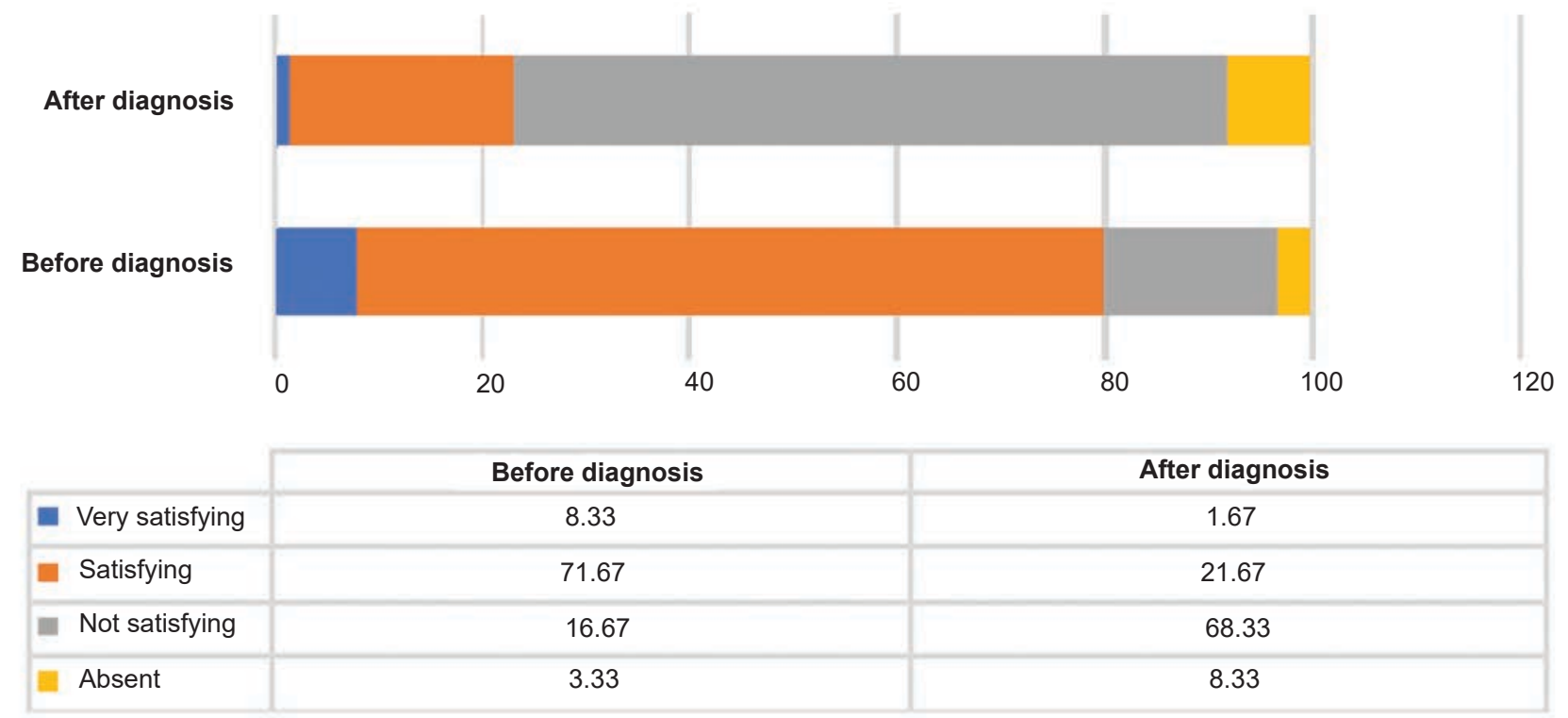

FIGURE 2. Self-evaluation of sexual life before and after rheumatic disease diagnosis

\section{Influence of diagnosis on sexual function}

$8.33 \%$ of the patients described their sexual life as being very satisfying before rheumatic condition diagnosis, $71.67 \%$ as being satisfying, $16.67 \%$ not satisfying, while $3.33 \%$ as being absent. After rheumatic condition diagnosis, only $1.67 \%$ described their sexual life as being very satisfying, while $21.67 \%$ as being satisfying, $68.33 \%$ as not satisfying and $8.33 \%$ as absent. 54 patients reported that their sexual life changed after rheumatic condition diagnosis: $86.36 \%$ of the ankylosing spondylitis patients, $90 \%$ of the rheumatoid arthritis patients, $90 \%$ of the scleroderma patients, $91 \%$ of the psoriatic arthritis patients, $87.5 \%$ of the gout patients. In $7(11.66 \%)$ cases sexual life quality declined after rheumatic condition diagnosis ( 4 cases - absent from satisfying, 2 cases - satisfying from very satisfying, 2 cases - not satisfying from very satisfying, 1 case - from not satisfying to absent). Only in 4 patients $(6.66 \%)$ sexual life quality improved after rheumatic condition diagnosis (1 case from not satisfying to satisfying, 1 case from absent to not satisfying).

Data regarding erectile dysfunction (ED) for each rheumatic disease and comparative data between study group and control group are presented in table 1. Most patients presented with mild erectile dysfunction, while most of the systemic sclerosis patients presented with mild to moderate erectile dysfunction. Compared to control group, each of analysed rheumatic disease and the whole study group had significant lower values of SHIM.

$24(40 \%)$ of the patients had diminished libido, significantly lower compared to the study group $(\mathrm{p}=0.043)$. Low libido was present in $16.66 \%$ of the ankylosing spondylitis patients, $10 \%$ of rheumatoid

TABLE 1. Sexual Health Inventory for Men questionnaire in study group and control group

\begin{tabular}{|c|c|c|c|c|c|c|c|}
\hline & $\begin{array}{c}\text { No erectile } \\
\text { dysfunction } \\
\text { (\%) }\end{array}$ & $\begin{array}{c}\text { Mild erectile } \\
\text { dysfunction } \\
\text { (\%) }\end{array}$ & $\begin{array}{l}\text { Mild to moderate } \\
\text { erectile } \\
\text { dysfunction (\%) }\end{array}$ & $\begin{array}{c}\text { Moderate } \\
\text { erectile } \\
\text { dysfunction (\%) }\end{array}$ & $\begin{array}{l}\text { Severe erectile } \\
\text { dysfunction (\%) }\end{array}$ & $\begin{array}{c}\text { Mean } \\
\text { SHIM } \\
\text { (SD) }\end{array}$ & t-test \\
\hline $\begin{array}{l}\text { Ankylosing } \\
\text { spondylitis }\end{array}$ & 13.63 & 68.18 & 0 & 0 & 19.04 & 19.04 & 0.048 \\
\hline $\begin{array}{c}\text { Rheumatoid } \\
\text { arthritis }\end{array}$ & 0 & 60 & 30 & 0 & 10 & 16.2 & 0.001 \\
\hline $\begin{array}{l}\text { Systemic } \\
\text { sclerosis }\end{array}$ & 0 & 22.22 & 55.55 & 22.22 & 0 & 14.88 & 0.015 \\
\hline $\begin{array}{l}\text { Psoriatic } \\
\text { arthritis } \\
\end{array}$ & 9.09 & 54.54 & 36.36 & 0 & 0 & 18.18 & 0.028 \\
\hline Gout & 0 & 87.5 & 0 & 12,5 & 0 & 18 & 0.042 \\
\hline Study group & 6.66 & 60 & 26.66 & 35 & 1.66 & 17.65 & 0.009 \\
\hline Control group & 16.66 & 68.22 & 13.33 & 1.66 & 0 & 20.15 & \\
\hline
\end{tabular}


arthritis and systemic sclerosis patients, $8.33 \%$ of the psoriatic arthritis patients and $8.33 \%$ of gout patients.

$83.33 \%$ of the patients felt their disease chaged their physical appearence; $84 \%$ of them felt that these chages influenced their relationships with other people. $94 \%$ of the patients reported chages in their psychological state and low self-esteem, the same procent reported influence of the disease on daily living. $81.66 \%$ of the patients reported physical influence of the rheumatic disease on their sexual life, main complains being articular pain (57.14\%), stiffness $(22.4 \%)$ and fatigue (13.33\%).

\section{Influence of disease activity and specific treatments on sexual function}

RA patients with active disease have significantly reduced SHIM scores compared to those with controlled disease $(p=0.02)$. We did not find correlation of disease duration with SD. AS patients with long standing disease and those with active disease had lower SHIM scores $(p=0.005$, respectively $p=0.01)$. For SSc patients we did not find any significant correlations with organ involvement, except for lung involvement $(p=0.001)$. We did not not find significant correlations of disease activity or disease duration for PsA patients. Disease duration does not seem to be correlated with SD for gout patients.
$20 \%$ of the patients used corticosteroids, $21.66 \%$ NSAIDs, 48.33\% biological therapy, 41.66\% synthetic DMARDs; $43.33 \%$ of the patients used associations.

$55 \%$ of the patients reported no influence of the treatment on their sexual life, $38 \%$ of the patients reported that specific treatment improved their sexual life, $7 \%$ of the patients related worsening of the sexual life after starting specific antirheumatic therapies. More then half $(65.21 \%)$ of the patients reporting improving of the sexual life due to specific rheumatic treatment were using biological therapies. The lowest SHIM scores were calculated for patients using corticosteroids (17.25) and DMARDs (17.24), while the highest SHIM scores were calculated for patients using NSAIDs (18.53). There was no statistical difference between SHIM scores of patients using biological therapies and other drugs

\section{DISCUSSIONS}

Sexual functioning is not part of questionnaires frequently used to assess physical function or quality of life. In a recent survey of ten rheumatologists, only $12 \%$ of patients seen in their practice were screened for sexual activity. The reasons given by rheumatologists were time constraints, discomfort with the subject, and ambivalence whether such a screening is in

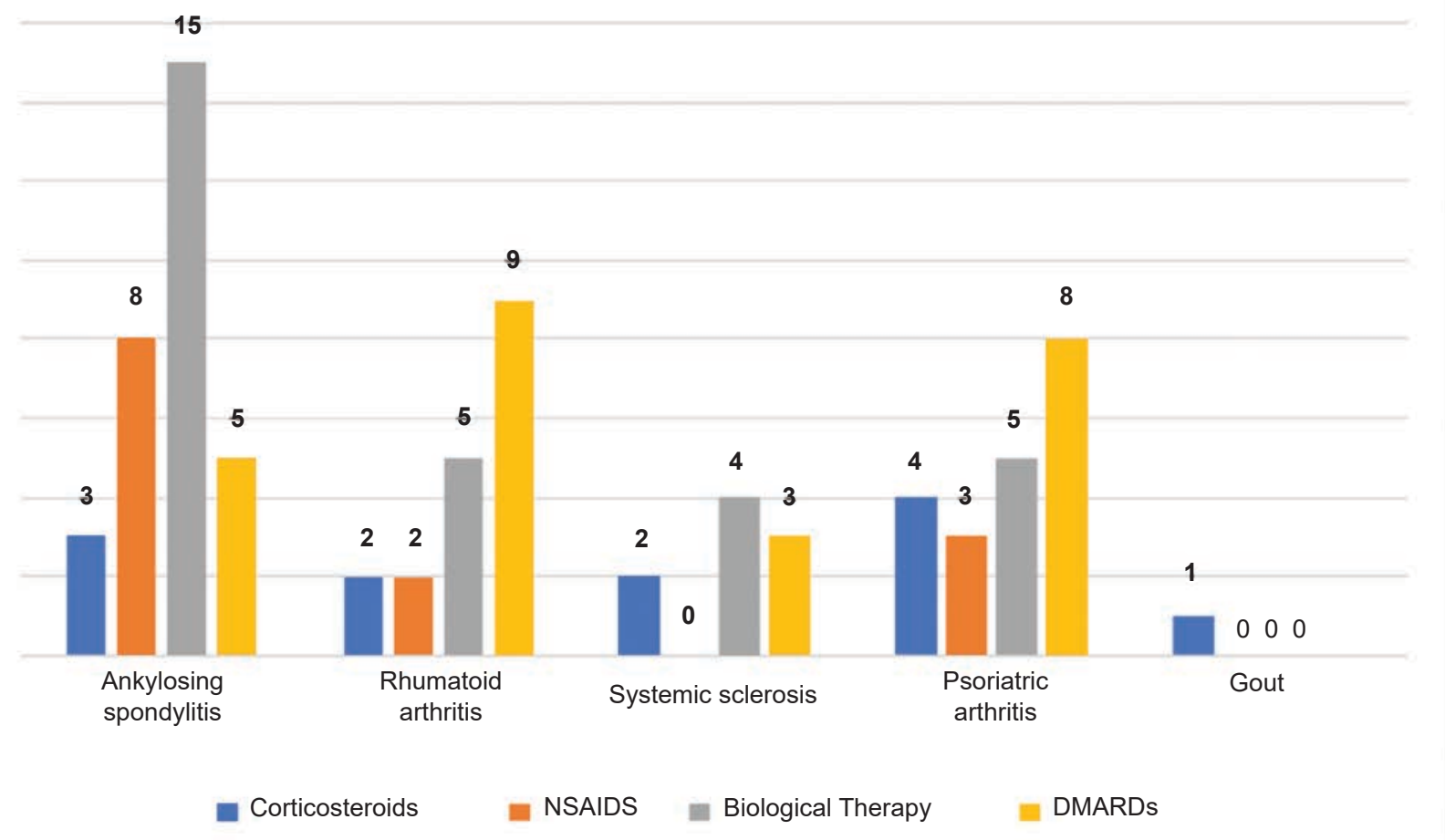

FIGURE 3. Therapies of study group. NSAIDs - nonsteroid antiinflammmatory drugs, DMARDs - disease modifying active rheumatic drugs 
their domain (8). It is therefore important that physicians or any other health professionals in charge of handling these kinds of patients raise the subject of sexuality and discuss it with them (9). There are barriers on the part of patients, either due to insecurity about mentioning the problem, because of the consideration that sexuality is not a disease, due to fear of a possible negative attitude on the part of the physician, or because of a belief that nothing can be done about sexual problems (10).

As predicted above, only $27 \%$ of interviewed patients in the clinic during the six months study accepted to complete an anonimous questionnnaire. The mean age of study group was 45 (4.37) years, normally a sexually active age. Most of the patients report their life as being satisfying before rheumatic disease diagnosis $(71.67 \%)$, but the quality of sexual life significantly decreased after rheumatic disease diagnosis (21.67\% - satisfying, $68.33 \%$ - not satisfying). $90 \%$ of RA, SS and PsA patients had a decline of their sexual life after diagnosis. Only in 4 patients $(6.66 \%)$ sexual life quality improved after rheumatic condition diagnosis.

Physical or emotional problems, hormonal changes, certain treatments and difficulties in the relationships of the patients with their partners, can contribute to a less active and often less satisfactory sex life (11). In phases of high activity, there can be a decrease in sexual desire because of chronic pain, fatigue and stiffness. On the other hand, changes in body image due to deformities can lead to a loss of self-esteem and a decline in sexual satisfaction. Pain during sexual relations, erectile dysfunction and difficulty in adopting certain positions are physical questions also related to sexuality that may lead to a loss of interest and in a decrease in the frequency of sexual relations $(11,12)$. RA, AS and PsA patients in our study grouphad lower SHIM scores compared with patients with controlled disease.

In our study group $83.33 \%$ of the patients reported changes of physical appearence related to rheumatic diagnosis. $84 \%$ of those patients correlated these changes to social relationships. $94 \%$ of our patients reported psychological changes and low self-esteem after diagnosis. $94 \%$ of the patients had impaired daily activities associated to rheumatic condition. $81.66 \%$ of the patients reported pain, articular stiffness and fatigue as main reasons of impaired sexual life.

Most patients reported low libido as being the predominant sexual dysfunction (40\%), followed by ED
(21.66\%). The number of rheumatic patients with low libido was significantly increased compared with control group $(\mathrm{p}=0.04)$. Patients in study group had significantly lower SHIM scores compared to control $(p=0.009)$. Patients with ankylosing spondylitis had the highest percent of reduced libido. For SS patients erectile dysfunction was the most predominant sexual dysfunction and they had the lowest SHIM scores.

In a recent metanalysis the prevalence of SD was significantly higher in men with RA than in healthy controls in all the included studies (range, 33-62\% vs. $11-40 \%$, respectively), this was associated with disease activity and other disease-related factors, such as fatigue and pain (13). $60 \%$ of the RA patients in our study group had a reduced libido after diagnosis and $30 \%$ of the had erectile dysfunction.

It was recently reported that $\mathrm{SD}$ can be a problem for $30-82.5 \%$ of male patients with AS, this was associated with disease activity, disease duration, depression, fatigue and limited joint mobility (13). In our study group the prevalence of low libido was $45.45 \%$ and $13.63 \%$ of AS patients had erectile dysfunction.

The prevalence of SD in men with SSc is very high, ranging from $60 \%$ to $100 \%$, the highest of all rheumatic diseases (14). The most likely hypothesis of ED in SSc is a combination of vascular and fibrotic abnormalities (14). These factors are also important in the pathogenesis of SD and the association between them and the presence of SD in men with SSc has been studied. In a EULAR report, ED was associated with severe cutaneous, muscular or renal involvement of SSc, elevated pulmonary pressures and restrictive lung disease. $66.66 \%$ of SS patients in our group had erectile dysfunction, $55.55 \%$ of them had moderate erectile dysfunction while in other rheumatic conditions mild erectile dysfunction was predominant, SS subgroup had the lowest SHIM scores in the patients group.

A pioneering study conducted in 1997 showed sexual dysfunction to be present in $40.8 \%$ of psoriasis patients, even after controlling for potential confounders such as alcohol consumption and depression (15). Feeling unattractive or embarrassed during psoriasis exacerbation can aggravate low self-confidence and erectile dysfunction (16). Atherosclerosis, which affects the vasculature of the pelvis, is considered the major cause of this dysfunction in males (16). Moreover, hormonal disturbance with decreased testosterone and increased estradiol, may be the reason for the significantly impaired erectile function (17). $45.45 \%$ of our PsA patients had low libido but 
only $9.1 \%$ of them reported mild erectile dysfunction.

A recent metanalysis showed that patients with gout were 1.44 times more likely to be diagnosed with ED when compared with control. This association existed in different age groups, even after adjustment of confounding covariates (18). A major impact was related to the acute and chronic joint pain and the associated disability, with physical and emotional impact on intimacy being the highest ranked responses. Moreover, the comorbidities associated with gout are closely connected with similar risk factors of vascular disease. ED is a common disease characterized by endothelial dysfunction, and uric acid itself causes endothelial dysfunction via decreased nitric oxide production and decreased vasodilator response to acetylcholine (19). The prevalence of ED was very high in our study group (87.5\%) maybe related to advanced age of the patients, compared to other rheumatic pathologies, to the fact that all patients were evaluated during hospitalization for disease flares and due to associated medical conditions (diabetes, arterial hypertension).

The impact of sexual dysfunction on men with rheumatic conditions is also reflected by the decreased rate of conception after diagnosis in our study group, only one patient with AS convieced after diagnosis.

Drugs used in the treatment of rheumatic diseases may also lead to sexual dysfunction. Methotrexate is associated with decreased libido, impotence and development of gynecomastia (20). Impotence has been reported with the use of hydroxychloroquine and sulfasalazine (20). Corticosteroids can have side effects with great impact on sexual function, with change in body image, as well as leading to depression and psychosis (20). The impact of biological therapies on sexual life and fertility of rheumatic patients is still a matter of debate, most data reporting improvement (21-23). We could not conclude that specific rheumatic medications had a definite role in the sexual life of rheumatic patients: $33.33 \%$ of the patients related improvement, while $55 \%$ of the patients reported no effect. In our group, biological therapies seem to improve sex life for the subgroups of RA, AS and PsA patients compared to other medication classes ( $p$ $=0.004$ ), although patients using combination of corticosteroids, biological therapies and DMARDs had the lowest SHIM scores.

\section{CONCLUSIONS}

Our study found that male patients with rheumatic diseases have a high prevalence of SD; this was statistically significant when comparing patients with rheumatic diseases to age matched healthy controls. We encourage rheumatologists to talk about sexual health with their patients. The use of widely available screening tools and early referrals to specialists should be considered in men with rheumatic diseases and $\mathrm{SD}$, especially those trying to conceive.

\section{Conflict of interest: none declared} Financial support: none declared

\section{REFERENCES}

1. Tristano AG. The impact of rheumatic diseases on sexual function and sexuality. In: Peterson NE, Campbell W (eds.). Handbook on Sexuality Perspectives, Issues and Role in Society. New York: Nova Science Publishers, 2012:75-97.

2. Mitchell KR, Jones KG, Wellings K, Johnson AM, Graham CA, Datta J, Copas AJ, Bancroft J, Sonnenberg P, Macdowall W, Field N, Mercer $\mathrm{CH}$. Estimating the Prevalence of Sexual Function Problems: The Impact of Morbidity Criteria. J Sex Res. 2016 Oct;53(8):955967.

3. Østensen M. New insights into sexual functioning and fertility in rheumatic diseases. Best Pract Res Clin Rheumatol. 2004;18:219232.

4. Fransen J, Welsing PMJ, De Keijzer RMH, Van Riel PLCM. Disease activity scores using c-reactive protein: CRP may replace ESR in the assessment of RA disease activity. Annals of the Rheumatic Diseases 2003;(62):151-158.

5. Machado P, Landewé R, Lie E, Kvien TK, Braun J, Baker D et al. Assessment of SpondyloArthritis international Society. Ankylosing Spondylitis Disease Activity Score (ASDAS): defining cut-off values

for disease activity states and improvement scores. Ann Rheum Dis. 2011;70(1):47-53.

6. Schoels MM, Aletaha D, Alasti F, et al. Disease activity in psoriatic arthritis (PsA): defining remission and treatment success using the DAPSA score. Annals of the Rheumatic Diseases 2016;75:811-818.

7. Valentini G, Bencivelli W, Bombardieri S, et al. European Scleroderma Study Group to define disease activity criteria for systemic sclerosis. III. Assessment of the construct validity of the preliminary activity criteria. Annals of the Rheumatic Diseases 2003:62:901-903.

8. Britto MT, Rosenthal SL, Taylor J, Passo MH. Improving rheumatologists' screening for alcohol use and sexual activity. Arch Pediatr Adolesc Med. 2000;154(5):478-483.

9. Serrant-Green L. Inequality in provision of sexual health information. Prof Nurse. 2001;16:1038-1042.

10. Helland Y, Dagfinrud H, Haugen MI, Kjeken I, Zangi H. Patients perspectives on information and communication about sexual and relational issues in rheumatology health care. Musculoskelet Care. 2017:(15):131-139. 
11. Xibillé-Friedmann D, Alvarez-Fuentes M, Flores-Flores G, GudiñoQuiroz J, Cruz-Valdez A. Percepción de la sexualidad en pacientes con enfermedades reumáticas: estudio piloto de casos y controles [Perception of sexuality in women with rheumatic disease: casecontrol pilot study]. Reumatol Clin. 2005;1(1):20-4.

12. Helland Y, Kjeken I, Steen E, Kvien TK, Hauge MI, Dagfinrud H. Rheumatic diseases and sexuality: disease impact and selfmanagement strategies. Arthritis Care Res. 2011;(63):743-750.

13. Perez-Garcia LF, Te Winkel B, Carrizales JP, Bramer W, Vorstenbosch S, van Puijenbroek E, Hazes JMW, Dolhain RJEM. Sexual function and reproduction can be impaired in men with rheumatic diseases: A systematic review. Semin Arthritis Rheum. 2020;50(3):557-573.

14. Foocharoen $\mathrm{C}$, Tyndall $\mathrm{A}$, Hachulla $\mathrm{E}$, et al. Erectile dysfunction is frequent in systemic sclerosis and associated with severe disease: a study of the EULAR Scleroderma Trial and Research group. Arthritis Res Ther. 2012;14(1):R37.

15. Gupta MA, Gupta AKI. Psoriasis and sex: a study of moderately to severely affected patients. Int J Dermatol. 1997;36(4):259-62.

16. Duarte GV, Calmon H, Radel G, de Fátima Paim de Oliveira M. Psoriasis and sexual dysfunction: links, risks, and management challenges. Psoriasis (Auckl). 2018;8:93-99.
17. Eltaweel A, Mustafa Al, El-Shimi OS, Algaod FA. Sex hormones, erectile dysfunction, and psoriasis; a bad friendship! Int J Dermatol. 2018; 57(12):1481-1484.

18. Du XL, Liu L, Song W, Zhou X, Lv ZT. Association between Gout and Erectile Dysfunction: A Systematic Review and Meta-Analysis. PLoS One. 2016;11(12):e0168784.

19. Salem S, Mehrsai A, Heydari R, Pourmand G. Serum uric acid as a risk predictor for erectile dysfunction. The Journal of Sexual Medicine. 2014;11(5):1118-24.

20. Almeida PH, Castro Ferreira CD, Kurizky PS, Muniz LF, Mota LM. How the rheumatologist can guide the patient with rheumatoid arthritis on sexual function. Rev Bras Reumatol. 2015;55(5):458-63.

21. Ruiz-Villaverde R, Sánchez-Cano D, Rodrigo JR, Gutierrez CV. Pilot study of sexual dysfunction in patients with psoriasis: influence of biologic therapy. Indian J Dermatol. 2011;56(6):694-699.

22. Oh JS, Heo HM, Kim YG, Lee SG, Lee CK, Yoo B. The effect of anti-tumor necrosis factor agents on sexual dysfunction in male patients with ankylosing spondylitis: a pilot study. Int J Impot Res. 2009;21(6):372-5.

23. Cooley LF, Wren J, Keeter MK, Lam I, Bennett N, Brannigan RE. Anti-TNF agents and potential effects on male fertility: are men being counseled? BMC Urol. 2020;20(1):111. 